\title{
Revisitando
}

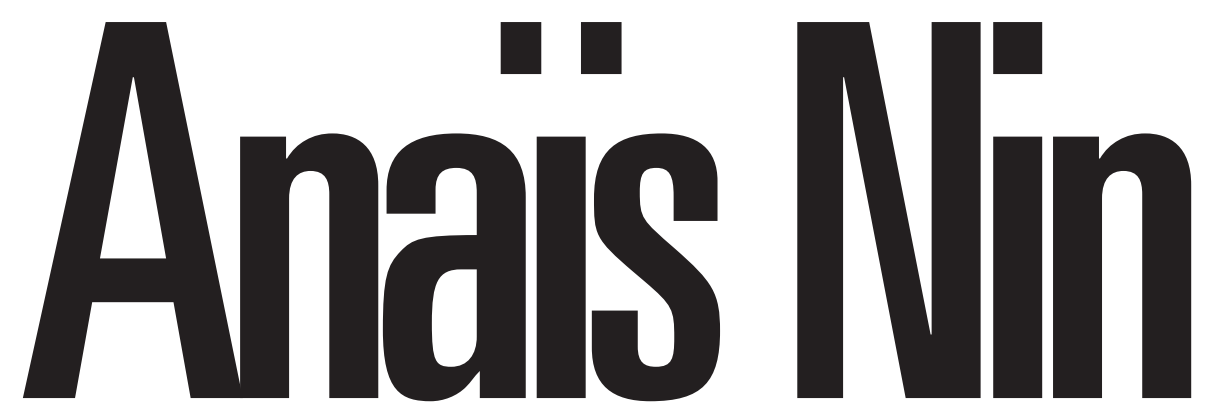

\section{A PRIMEIRA ANAÏS}

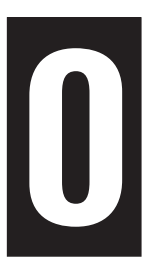

s quatro primeiros volumes dos

Diarios de Anats Nin, publicados entre 1966 e 1971, representaram para as mulheres dos anos 70, em busca de arte e liberdade, uma eclosão, um novo exemplo e modelo. Eram os fios do sonho, da arte, da integridade interior, da ternura, do afeto, do erotismo, preservados a duras penas, com muito esforço. Manter a leveza e a poesia, acolher amorosamente amigos, amantes, família, construir a harmonia, cuidar, apoiar, sustentar-e sobretudo escrever e criar como alvo primordial, viver a paixão sem tabus, desprezando proibições e convenções -, Anaïs parecia reunir o inalcançável. Sedutora, lá estava aprendendo a dança espanhola das ciganas, para se apresentar no palco e melhor enfeitiçar os admiradores. Escritora, sacrificava boa parte de seu tempo e energia para abrigar os desvalidos, ou estimular os artífices de sua profissão, como Henry Miller ou Antonin Artaud, no ímpeto de criação, desfazendo nós que os impediam de fluir. Desprendida, abria mão do próprio dinheiro para ajudar os outros - é verdade que à custa de um marido próspero que não aparece no diário. Subtraía da mesada com que era mantida o necessário para alimentar uma extensa rede de afetos, “as suas crianças", todos adultos aventureiros e boêmios. Pautar a vida pela imaginação, não pelas circunstâncias, guiar-se pelo espírito, pela sensualidade, pelos dons artísticos, esta a sua lei, a de uma mulher muito especial.

Diferenciava-se de outras escritoras igualmente firmes e independentes, desbravadoras, como Simone de Beauvoir ou Doris Lessing, ou de figuras poéticas de grandes criadoras, como Virginia Woolf, ou mais recentes que ela, como Natalia Ginzburg, pois era ousada na vida pessoal, símbolo dos arquétipos tradicionais da amorosa mas também da amazona autônoma que não se dobra à vontade masculina e, ao contrário, joga com os homens com grande habilidade.
BETTY MINDLIN

é antropóloga e autora de, entre outros, 0 Primeiro Homem, São Paulo, (Cosac \& Naify). 
A obra erótica, feita para ganhar dinheiro, literariamente menor, fazia parte do encantamento provocado por Anaïs, por ser pioneira e corajosa, avançada como escrita feminina sobre sexo, mantendo porém um enredo romanesco e poético, por mais que os editores sempre lhe encomendassem mais pornografia. Em Delta de Vênus, a cortesã Anaïs, com um saber do corpo, da poligamia e do amor só de experiências feito, era bem mais nítida que no autoretrato dos Diarios. Os romances atraíam menos que os Diarios - estes mais redondos e bem escritos, cheios de míticas figuras de personagens importantes, escritores nascendo ou florescentes, Lawrence Durrell, Henry Miller, Antonin Artaud, cineastas como Maya Deren retratando o Haiti e o vodu tão próximodo candomblé, e tantos outros. Anos dourados entre as duas grandes guerras, em Paris, Barcelona, Nova York, com Cuba, o país de origem, como pano de fundo.

Havia a descoberta de Freud, da psicanálise, do prazer, do teatro e do cinema, da invenção em todas as suas formas, como a de viver - apenas ficando excluído, da parte de Anaïs, o envolvimento político ou engajamento social direto, embora lesse Marx, ouvisse em comícios "La Pasionária" ou Malraux, entre outros, escrevesse sobre a Guerra Civil Espanhola, greves e organização de trabalhadores.

Anaïs Nin era voltada para "o que não existe”, como diria Darcy Ribeiro, o que é construído com a fibra da fantasia, a ficção. Era desatenta aos bens materiais e à acumulação, esbanjando os parcos recursos em produtos de beleza, perfumes, roupas exóticas, comida para os amigos, viagens para todos, livros, música, tudo o que fosse instrumento para enlouquecer homens e possíveis amantes.

A magia dos diários tinha lacunas óbvias. Ela não tinha filhos, e nada explicava sobre o assunto nem se faziam falta. Era maternal com os amigos, a ponto de escravizar-se em tarefas domésticas de cozinhar, lavar, cuidar, curar, providenciar médicos e remédios, exatamente como uma esposa tradicional, com uma carga muito maior, porém, pois estava voltada para múltiplos senhores. Nada aparecia de concreto sobre a vida sexual, ou sobre o marido - nem sequer se sabia se existia, ficava nebuloso se os personagens masculinos eram de fato amantes ou amigos, como o primo Eduardo, os dois psicanalistas, René Allendy e Otto Rank, o revolucionário peruano Gonzalo, Henry Miller e muitos outros. Costumavam segui-la a toda parte, alguns até para outro continente, como Rank ou Henry Miller, que com ela transferiram a vida de Paris a Nova York.

Eduardo, o primo, uma de suas primeiras paixões, que mais tarde revelou-se homossexual, abriu a Anaïs o caminho para o surrealismo a psicanálise. Foi o primeiro a the recomendar fortemente uma psicanálise e a falar de Freud, que ela desconhecia e que o marido Hugo propôs que lessem para saber se valia a pena a aventura: concluíram afirmativamente. Anaïs acabou se tornando também psicanalista, através de Otto Rank, e se sustentou um bom tempo com a clínica em Paris e em Nova York.

\section{DESENCANTO}

O brilho exemplar da descoberta dessa deusa escritora empanou-se muito quando surgiram, quase duas décadas depois, os primeiros diários sem censura, recriados e editados: Henry e June e Incesto. Nós, leitores, nos sentimos como maridos traídos ao descobrir os muitos namoros e transgressões. Os diários nos haviam induzido a ver uma dança sem pecados, a expansão de uma mulher em flor. E ela, tão fiel a si mesma, havia omitido o melhor da festa, de maior impacto? Por que tanta censura? Depois soubemos, por exemplo através da biografia de Anaïs Nin escrita por Deirdre Mair, que as editoras temiam processos por parte das pessoas envolvidas, este um motivo ainda mais importante para os cortes que o respeito a marido e amantes, ou mais cruamente, que a penumbra necessária sobre as muitas maneiras de enganá-los.

O belo, intenso, original romance com Henry Miller, até já transposto para o cinema com a atriz magnífica e tão próxima 
de Anaïs que é Maria Medeiros, era um soco no estômago, como se nós, leitores, estivéssemos sendo ludibriados com torpeza. Por que não ter nos contado antes, quando tínhamos a mesma idade que a protagonista, e seríamos solidários ou teríamos um ponto de apoio para nossas vidas? A duplicidade e a mentira nos feriam, embora todos saibam que existem sempre no amor múltiplo. Esse era o preço de viver a verdade, comum a tantos homens e mulheres que amam muito - o dilema de saber onde está a fidelidade. No caso de Anaïs, a compulsão à mentira parecia ter um elemento adicional; a insegurança em relação à figura paterna fugidia, e uma imitação do comportamento do pai, Don Juan sempre cercado de belas amantes.

O mais insuportável à leitura da obra sem censura de Anaïs, publicada tantos anos depois, foi enfrentar os dois cânones sagrados que ela derrubou: a proibição do incesto e a maternidade.

O romance com o pai, que ela não via há vinte anos, foi vivido aparentemente sem remorsos, compensação para uma infância de abandono, máxima sedução. Anaïs tinha outros amores simultâneos além do marido, mas, na época do namoro proibido, o pai tornou-se o rei na escala dos desejos. Finda a paixão, ela o descartou com crueldade, como fora, aos 11 anos, cortada desse pai músico e compositor, artista e sedutor.

É possível ignorar com tanta semcerimônia o laço de família, mesmo com a desculpa da ausência paterna por longos anos? Por vezes, nós leitores, que havíamos lido e descoberto juntos a Anaïs do princípio, nos consolávamos pensando que ela poderia estar inventando o episódio, assim como ela afirma ter talvez forjado o assédio sexual do pai em sua infância, não sabendo mais o que foi ou não a verdade. A biógrafa de Anaïs, Deirdre Mair, porém, nem sequer sugere a hipótese de ficção, não põe em dúvida a realidade chocante; e de fato, por que não tomar a sério a descrição, quando o incesto é mesmo muito freqüente?

Ainda mais terrível que a paixão pelo pai é o texto sobre o aborto provocado aos 6 meses de gravidez - completa recusa da maternidade. Claro que é possível entender os motivos potenciais: a infância dolorosa, a mãe abandonada, o desejo de escrever conflitante com a domesticidade, a ignorância sobre quem era o pai biológico do seu bebê em gestação (embora ela afirmasse que era Henry Miller, não era possível ter certeza, havia mais de três candidatos, incluindo talvez o próprio pai, avô do nascituro!). Ela deve ter hesitado nos primeiros meses, em que o aborto seria uma experiência corriqueira e comum a tantas mulheres - talvez tenha arrastado irresponsavelmente a decisão, com alguma secreta ponta de desejo de ter um filho.

A descrição do "parto" provocado, que levou vários dias com grande sofrimento, é mais que repugnante. Marido e amantes amparando-a no hospital, reunidos em torno da recusa do fruto bem visível num ventre - anseio fundamental da maioria das mulheres. A frieza aparente de Anaïs, enfrentando a dor sem queixas, mas muito decidida a esse quase assassinato, é um contraste desagradável com a sensibilidade, leveza, ternura, passionalidade que ela simbolizou durante tanto tempo. Houve outros abortos, mas então muito mais dentro do que é aceitável. Este, transformado por ela em literatura, é cruel, e a descrição feroz.

\section{UMA REVISÃO}

Outro período de vários anos de distância de Anaïs Nin, até ler seu ensaio (embora publicado em 1976, antes de Incest, queé de 1992) In Favour of the Sensitive Man and Other Essays, um raro manifesto sobre erotismo e sua expressão na escrita, arte difícil e relativamente nova para as mulheres, a de transmitir a experiência do amor sensual, sem crueza, com sentimento, mas evitando o pudor, a metáfora e a evasão excessivos.

Para a reconciliação final com Anaïs, surgiu em 1995 a magnífica biografia escrita por Deirdre Mair (também biógrafa de Simone de Beauvoir e Samuel Beckett), em si um livro capaz de sustentar o entusiasmo e prender a atenção ao longo de 550 páginas. A 
história dos pais de Anaïs e de sua infância é um episódio fascinante do livro. Rosa, a mãe de Anaïs, cubana de uma família tradicional, era uma mulher forte, que lutou para se casar com um compositor bem mais novo que ela, originário de Barcelona, muito pobre. O casamento foi desastroso. Joaquin, o pai de Anaïs, foi se revelando com os anos um tirano, até mesmo espancando a mulher e os filhos, e os abandonou quando Anaïs tinha 11 anos. Rosa, que sempre contou com a forte solidariedade da família cubana, foi aprendendo a se tornar independente e até bem-sucedida na arte de ganhar dinheiro. Anaiis adorava o pai, que a distância tornouse ainda mais mítico, e está na origem dos seus diários, escritos como uma correspondência com ele, mesmo sem resposta. Uma descoberta é perceber que, apesar da situação familiar opressiva, da discórdia, do drama, da violência doméstica, havia a chama da música, do canto, da eternidade. Rosa cantava com Joaquin nos concertos e o clima de arte foi sempre a bússola na vida de Anaïs.

Outra revelação que surpreende na biografia é a inexperiência e mesmo puritanismo de Anaïs até a fase de Henry Miller. Casou-se aos 20 anos com Hugo Guiler, apesar da oposição da família dele a uma moça pobre e católica. Eram muito apaixonados - mas com uma grande ignorância e ingenuidade relativas ao corpo e à sexualidade. Anaîs conta nos diários inexpurgados que juntos queriam descobrir o que era a vida sexual possível e experimentada à sua volta, e vão um dia observar duas prostitutas transando. Ficam sabendo só então o que é o clitóris, e qual o seu papel... e se beneficiam do aprendizado. É bem aos poucos, passo a passo, que uma Anaïs de fogo vai se revelando, instintiva, sensual, sem pudor de atrair todos os homens, solta e sem peias morais. Sua relação com o marido é construída inicialmente de modo bastante tradicional, ela vendo o papel de uma esposa como o de forjar um artista e lhe dar condições de plena realização.

A partir dos 30 anos, a característica marcante de Anaïs é uma extraordinária força voltada para a escrita e para o sexo.
Os seus diários compreendem 250 mil páginas-escritos em aproximadamente 60 anos, representam uma média diária de mais de dez páginas! Tinha uma compulsão a gravar a vida, vivia para registrar por escrito, escrevia, reelaborava e novamente recriava o que fizera. Os amigos e analistas julgavam uma doença essa obsessão, apontavam a compulsão ao diário como contradizendo a ficção: ser fiel aos fatos tirava-lhe energia para inventar enredos e personagens. Ela não consegue jamais interromper os diários, que a acompanham sempre, são sua maior preocupação nas mudanças, nas guerras, com esconderijos para não serem lidos pelos múltiplos homens, a não ser com censura.

Cabe aos críticos que leram bem a obra ficcional de Anaïs julgar se os diários são mais bem-sucedidos que os romances ou não - a verdade é que se tornaram muito mais conhecidos. A fama chegou tarde na vida de Anaïs, uma de suas grandes dores, pois enquanto os seus amigos de juventude se transformaram em mitos-Miller ou Durrell, por exemplo - ela era mais procurada por sua intimidade com eles e teve grande dificuldade em ser publicada. A energia de sua dedicação à escrita só foi igualada pela intensidade do desejo sexual-que voracidade! Estava sempre cercada de um boa quantidade de amantes, cuidando de todos como de uma família, substituindo a maternidade que recusou. Insatisfação ou plenitude?

Anaïs pagava um preço por mergulhar na paixão. Vivia dilacerada, numa imensa divisão, adoecia, tinha depressões, precisava ser internada e recorria aos psicanalistas, sentia-se culpada em relação a cada homem - o outro lado dos dias solares. Chegou a ser bígama do ponto de vista legal. O namorado e companheiro mais jovem, Rupert Pole, acreditando no que Anaïs the contava, julgou que ela houvesse se separado de Hugo Guiler, o marido, e levou-a a um cartório do México; casaram-se, ela não conseguiu recusar a felicidade. Anaïs foi obrigada às mentiras mais absurdas, com dois nomes de casada, tentando até mesmo controlar críticos literários e jornalistas nas notícias, forjando desculpas para estar meses na Califórnia e outros em Nova York, 
com cada marido, omitindo números de telefone, apresentando falsos empregos e endereços, escondendo de Rupert que o dinheiro que lhe dava provinha do marido legítimo e não de trabalhos, etc. É difícil imaginar maiores contradições, ou dispêndio de tempo e alma com tantos estratagemas. Apenas nos últimos anos de vida ela conseguiu resolver o dilema e abrir a verdade (com mais franqueza ao segundo marido), solução que ela atribui aos anos de psicanálise, principalmente com a última analista, uma mulher, em longo processo que a fez atingir a paz almejada.

Quando se contempla e se tem acesso a tantos dados em profundidade sobre uma vida terminada, um outro sentido aparece, que faz parecer supérflua a pergunta que surgia antes: se estávamos diante de um monstro ou de um modelo. Não é tanto a duplicidade que chama a atenção, mas os impulsos opostos estraçalhando um caminho de mulher. Não querendo deixar Hugo, o marido, Anaïs ia vivendo o outro amor, como em geral fazem os infiéis - mas não com frieza e irresponsabilidade, e sim com uma lealdade e gratidão ao primeiro companheiro, que não queria esfacelar. Em todas as vidas de mulheres, pelo menos em semente, existem esses contrastes entre desejos realizados e irrealizáveis, como o conflito maternidade/criação. Anaïs perseguiu uma verdade interior, a fantasia - à sua moda, é verdade -, à custa de causar e viver muito sofrimento, mas de modo radical. Com todos os desapontamentos e percalços, continua a ser a dançarina espanhola sedutora, escritora iluminando trilhas possíveis para as mulheres não-conformistas.

Os maridos foram, de certa forma, recompensados pela ironia do destino. Hugo, que era umempresáriorico, começou a perder seus bens a partir da Revolução Cubana e ficou pobre. Passou a viver dos direitos autorais de Anaïs, que nos últimos anos de vidaficou famosa ganhou dinheirocom seus livros. Mesmo depois da morte de Anaïs, Hugo ficou bem de vida, graças aos proventos dos livros eróticos, os que verdadeiramente fizeram sucesso. Todo o resto da obra e a curadoria dos Diarios ficaram com o marido escolhido no final como o único, Rupert (um neto de Frank Lloyd Wright), dezesseis anos mais novo que Anaïs, apaixonadíssimo e dedicadíssimo a ela.

A vida amplamente descrita de Anaïs faz ressaltar o destino humano: a resistência de tanta gente a abandonar as "relações eternas", tidas como tal, as instituições e laços sagrados, o tempo que leva desenraizar-se e plantar em outro lugar, largar um casamento e reconhecer que se transformou. A amoralidade aparece como a complexa teia das emoções, jamais ou raras vezes claras e bem-delineadas, com um tempo de maturação e crescimento.

\section{BIBLIOGRAFIA}

DEIRDRE, Mair. Anaïs Nin. A Biography. Londres, Bloomsbury, 1995.

DEREN, Maya. Divine Horsemen. The Living Gods of Haiti. London, Thames and Hudson, 1953.

NIN, Anaïs. Delta of Venus. New York, Harcourt Brace Jovanovich, 1969.

The Diary of Anaïs Nin. Volume I 1931-1934. New York, Harcourt Brace Jovanovich, 1966.

. The Diary of Anaïs Nin. Volume II 1934-1939. New York, Harcourt Brace Jovanovich, 1967.

The Diary of Anaïs Nin. Volume III 1939-1944. New York, Harcourt Brace Jovanovich, 1969.

. The Diary of Anaïs Nin. Volume IV 1944-1947. New York, Harcourt Brace Jovanovich, 1971.

. In Favour of the Sensitive Man and Other Essays. New York, Harcourt Brace Jovanovich, 1976

(Londres, Penguin, 1992).

. Henry and June. New York, Harcourt Brace Jovanovich, 1986.

. Incest. From "A Journal of Love". The Previously Unpublished, Unexpurgated Diary, 1932-34. New

York, Harcourt Brace Jovanovich, 1992.

. Little Birds: Erotica. New York, Pocket Books, 1990. 